\title{
Actividades lúdico-práticas no ensino da Geologia: complemento motivacional para a aprendizagem
}

\author{
Andreia Constante \\ Aluna de Mestrado, Depto. Geociências, Ambiente e \\ Ordenamento do Território, Rua do Campo Alegre, 4169-007 \\ Porto, Portugal, constanteandreia@portugalmail.pt \\ Clara Vasconcelos \\ Professora Auxiliar, Depto. Geociências, Ambiente e \\ Ordenamento do Território, Centro de Geologia, Univ. do \\ Porto, Rua do Campo Alegre, 4169-007 Porto, Portugal, \\ csvascon@fc.up.pt
}

*Este artigo deve ser
referido como segue:

A. Constante, C. Vasconcelos 2010. Actividades lúdicopráticas no ensino da geologia: complemento motivacional para a aprendizagem. Terræ Didatica, $6(2): 101-$ $123<$ http: $/ /$ www. ige.unicamp.br/ terraedidatica/>

\begin{abstract}
PLAYFUL AND PRACTICAL ACTIVITIES IN GEOLOGY TEACHING: MOTIVATIONAL COMPLEMENT FOR LEARNING. It 's unanimous that the teaching of Geology, in the training of individuals, should not limit itself to its scientific features. It is also essential to invest in its formative character since the lowers levels of teaching. The lack of research in this area justifies this investigation, which intended to evaluate the advantages in the application of playful and practical activities as strategic complements. They act as facilitator's elements in Geology teaching and learning processes. The research methodology adopted was Research \& Development with the aim to develop, implement and evaluate two recreational and practical activities. These ones were applied to 71 students of a portuguese public school. Data collecting instruments were elaborated, such as questionnaires and observation reports. The evidences showed that playful and practical activities are valuable strategic complements in the processes of teaching and learning, allowing us to advocate more time and space for them in the teaching process.
\end{abstract}

KEYWORDS Playful and practical activities, teaching geology, learning geology, motivational complement, learning.

RESUMO É unânime que o Ensino das Geociências, na formação dos indivíduos, não deve resumir-se ao seu carácter científico, sendo imprescindível, outrossim, investir no seu carácter formativo desde os niveis mais básicos do ensino. A escassez de pesquisas neste âmbito justifica a presente investigação que pretendeu contribuir para aferir as mais-valias da aplicação de actividades lúdico-práticas como complementos alternativos e inovadores, actuando como elementos facilitadores no processo de ensino e aprendizagem da Geologia. A metodologia adoptada foi a Investigação \& Desenvolvimento que visou a elaboração, aplicação e avaliação de duas actividades lúdico-práticas. As duas actividades lúdico-práticas foram aplicadas a 71 alunos de uma escola pública em Portugal. Administraram-se instrumentos de recolha de dados como, por exemplo, questionários e relatórios de observação. Constatou-se que as actividades eram complementos motivacionais valiosos no processo de ensino e aprendizagem de conceitos com algum nivel de abstraç̧ão, permitindo advogar um espaço e tempo maiores para a sua utilização na prática pedagógica.

PALAVRAS-CHAVE Actividades lúdico-práticas, ensino da geologia, aprendizagem da geologia, complemento motivacional, aprendizagem. 
O conhecimento é, pois, "uma aventura incerta que comporta em si mesmo, permanentemente, o risco de ilusão e do erro".

Edgar Morin

\section{Introdução}

A relevância do trabalho prático no Ensino das Ciências é amplamente reconhecida, não só por investigadores e professores de diversos níveis de ensino mas também por decisores de políticas educativas e de curricula (Oliveira 1999). Neste estudo (integralmente apresentado na dissertação de Mestrado de Constante 2009) aplica-se o termo "actividade lúdico-prática" a todas as actividades de cariz lúdico, em que o aluno está activamente envolvido na sua concretização. Actualmente, é inquestionável que as actividades práticas têm centrado a atenção de educadores e investigadores da área da Educação em Ciências. Contudo, tem sido ampla a confusão nas escolas e mesmo entre investigadores sobre o significado a imputar aos termos "prático", "laboratorial" e "experimental", o que, no contexto do Ensino das Ciências, importa clarificar.

Seguindo a perspectiva apresentada por Leite (2001), baseada em trabalhos anteriores de Hodson (1988), os três termos referem-se a actividades cujas características podem ou não confluir simultaneamente na mesma. A designação "actividade prática" (AP) aplica-se a todas as actividades em que o aluno está activamente envolvido na realização de uma tarefa. Se analisarmos este envolvimento ao nível psicomotor, cognitivo ou afectivo, a AP pode incluir actividades laboratoriais, trabalho de campo, actividades de resolução de problemas de lápis e papel, pesquisa bibliográfica sobre um dado assunto; mas já o não é assistir à exposição de um tema ou à realização de uma demonstração pelo professor, ainda que de cariz laboratorial. Por "actividade laboratorial" (AL) entende-se um conjunto de actividades que decorrem no laboratório (ou numa sala normal, desde que não acarrete riscos para a saúde e/ou segurança), com materiais e/ou equipamentos próprios. A AL só será considerada uma AP, se o aluno for o executante da mesma. De salientar que, os materiais e/ou equipamentos também podem ser utilizados num lugar ao ar livre (onde os fenómenos ocorrem ou os materiais existem), designando-se, neste caso, as actividades por "actividades de campo". Quanto à "actividade experimental" (AE), o termo aplica-se às actividades práticas onde há controlo e manipulação de variáveis e que podem ser laboratoriais, de campo ou outro tipo de actividades práticas.

A figura 1 ilustra a relação que existe entre os três tipos de actividades referidas anteriormente.

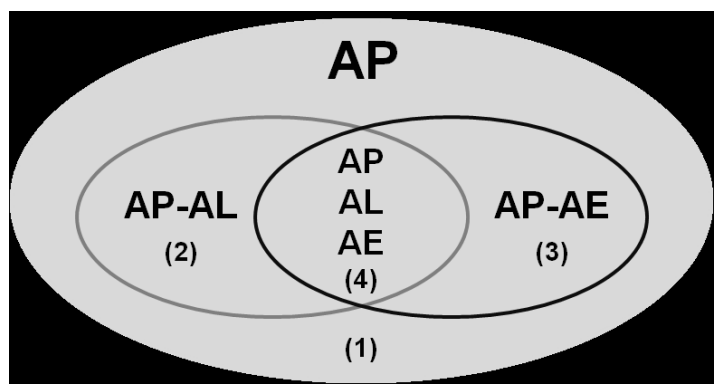

Figura 1 - Relação entre actividade prática, laboratorial e experimental (adaptado de Martins et al. 2007)

Pela análise da figura 1, constata-se que (Martins et al. 2007):

- na área (1) situa-se a actividade prática que não é do tipo laboratorial, nem do tipo experimental;

- na área (2) situa-se a actividade prático-laboratorial que não é do tipo experimental (por exemplo, a aprendizagem de técnicas laboratoriais);

- na área (3) situa-se a actividade práticoexperimental que não é do tipo laboratorial, logo não utiliza equipamentos de laboratório;

- na área (4) situa-se a actividade práticolaboratorial-experimental, onde se inserem as de grau de abertura variável, através das quais o aluno deverá encontrar resposta a uma questão inicial.

Como foi comprovado por Piaget, as actividades de natureza prática sempre foram consideradas importantes para as crianças, principalmente nas faixas etárias mais baixas, como forma de potenciar a sua ligação com o mundo exterior, sendo esta fundamental para o desenvolvimento do próprio conhecimento. De salientar, no entanto, que a simples manipulação de objectos e instrumentos não implica obrigatoriamente a geração de conhecimento. É imprescindível questionar, reflectir, interagir, responder a perguntas, planear e confrontar opiniões, para que uma actividade prática possa desenvolver nos alunos o desafio intelectual que os mantenha interessados em desejar compreender fenómenos, relacionar situações, desenvolver interpretações e elaborar previsões (Martins et al. 2007).

Segundo Wellington (1998), sendo o trabalho prático adequadamente conduzido, os argumentos a favor da sua utilização podem classificar-se em 
três domínios: cognitivo, afectivo e processual. O quadro 1 resume os objectivos a favor da actividade prática, frequentemente referidos por vários investigadores (Tamir 1991, Hodson 1993, Wellington 1998, Miguéns1999).

Quadro 1 - Objectivos da actividade prática (adaptado de Martins et al. 2007)

\begin{tabular}{|c|c|}
\hline Domínio & Objectivos da AP \\
\hline Cognitivo & $\begin{array}{l}\text { - Ilustrar a relação entre variáveis, importante } \\
\text { na interpretação do fenómeno. } \\
\text { - Ajudar a compreensão de conceitos. } \\
\text { - Realizar experiências para testar hipóteses. } \\
\text { - Promover o raciocínio lógico. }\end{array}$ \\
\hline Afectivo & $\begin{array}{l}\text { - Motivar os alunos. } \\
\text { - Estabelecer relações/comunicação com } \\
\text { outros. } \\
\text { - Desenvolver atitudes críticas no trabalho } \\
\text { de equipa. }\end{array}$ \\
\hline Processual & $\begin{array}{l}\text { - Proporcionar o contacto directo com os } \\
\text { fenómenos. } \\
\text { - Manipular instrumentos de medida. } \\
\text { - Conhecer técnicas laboratoriais e de cam- } \\
\text { po. } \\
\text { - Contactar com metodologia científica. } \\
\text { - Fomentar a observação e descrição. } \\
\text { - Resolver problemas práticos. }\end{array}$ \\
\hline
\end{tabular}

De salientar que nem todas as actividades práticas cumprem com todos os objectivos, anteriormente mencionados. Tudo depende do que se pretende alcançar através da sua realização. O que distingue as actividades não é, pois, o fenómeno (actividades diferentes podem centralizar-se sobre o mesmo fenómeno), mas o procedimento seguido.
Segundo Caamaño (2007), podem considerarse quatro tipos de actividades práticas (quadro 2), tendo em conta o grau de elaboração crescente das tarefas a realizar.

Considerando a motivação como um requisito necessário e potenciado das aprendizagens, o Ensino das Ciências, nomeadamente o Ensino da Geologia, deve permitir despertar e dirigir o aluno, promovendo a conquista de motivos para aprender, para se aperfeiçoar e para desenvolver e rentabilizar as suas competências. Contudo, há que considerar que a motivação dos alunos para as actividades da aula depende de muitos factores tais como a idade, sexo, aptidão intelectual, situação económica, social e familiar e traços individuais da personalidade (Balancho \& Coelho 2004).

\section{Actividades lúdico-práticas}

Desde o início do século XX que, sempre que se reflecte em torno do conceito de actividade lúdica, vários pontos de vista têm sido considerados, particularmente nos últimos cinquenta anos (Pessanha 2001). Contudo, por se tratar de uma área de investigação complexa onde várias perspectivas devem ser contempladas, não se conseguiu até aos dias de hoje encontrar um consenso. Christie \& Johnsen (1983) realçam que a variedade de componentes e domínios que podem ser relacionados com a actividade lúdica indicam a riqueza e a ambiguidade deste conceito, e que uma definição comum e universal tem sido sempre evitada pelos investigadores, uma vez que, sendo a actividade

Quadro 2 - Tipos de actividades práticas (Caamaño 2003, Martins et al. 2007)

\begin{tabular}{|c|c|}
\hline Tipo da AP & Características \\
\hline Experiências sensoriais & $\begin{array}{l}\text { Destinadas a obter uma familiarização perceptiva com os fenómenos. Baseiam-se assim na visão, } \\
\text { no olfacto, no tacto e na audição. }\end{array}$ \\
\hline Experiências ilustrativas & $\begin{array}{l}\text { Destinadas a ilustrar um princípio ou uma relação entre variáveis. Supõem, normalmente, uma } \\
\text { aproximação qualitativa ou semi-quantitativa ao fenómeno. }\end{array}$ \\
\hline Exercicíos práticos & $\begin{array}{l}\text { Concebidos para aprender determinados procedimentos, destrezas ou para realizar experiências } \\
\text { que ilustrem ou corroborem uma teoria. Têm um carácter especialmente orientado ("exercício"). } \\
\text { Dependendo dos objectivos pretendidos sobre essas actividades, pode-se distinguir entre exercícios } \\
\text { práticos para: } \\
\text { (a) a aprendizagem de competências específicas, que podem ser de natureza laboratorial, cognitiva } \\
\text { (interpretação, classificação, elaboração de hipóteses) e/ou comunicacional (planificação de uma } \\
\text { experiência, apresentação dos resultados, elaboração de um relatório escrito); } \\
\text { (b) a ilustração e verificação experimental de uma dada teoria. } \\
\text { Assim, na categoria de exercícios práticos cabem as actividades que se destinam a aprender métodos } \\
\text { e técnicas ou a ilustrar teorias. }\end{array}$ \\
\hline Investigações & $\begin{array}{l}\text { Visam dar aos alunos a oportunidade de encontrarem resposta a uma questão-problema e, por isso, } \\
\text { são conduzidas na perspectiva de trabalho científico. Proporcionam ao aluno o desenvolvimento da } \\
\text { compreensão de procedimentos próprios do questionamento e, através da sua aplicação, resolver } \\
\text { problemas de índole mais teórica ou mais prática (sendo, neste caso, normalmente emergentes de } \\
\text { contextos reais que lhe são familiares). }\end{array}$ \\
\hline
\end{tabular}


lúdica tão rica e diversificada, uma definição única poderia limitá-la.

$\mathrm{Na}$ expectativa de que as actividades lúdico-práticas potenciem uma melhoria da qualidade do ensino e da aprendizagem das ciências, a sua utilização surge como complemento à estratégia de ensino do professor (Lopes 2009). Neste estudo, não se perspectivam as actividades lúdico-práticas apenas no seu carácter de movimento, que tem como objectivo produzir prazer aquando da sua execução e que podem incluir jogos, brinquedos ou divertimento. Aqui, são também entendidas como uma necessidade básica da personalidade humana e assumidas como um complemento educativo motivador.

Caracterizadas pela sua atractividade, as actividades lúdicas despertam o interesse do aluno: fazem com que participe mais; obrigam ao diálogo com os seus colegas; instigam-no a ouvir opiniões diferentes sobre o tema abordado; apelam à reflexão, à colocação de questões, à construção e/ou alteração do seu conhecimento e à conscientização sobre o seu papel social no mundo. De acordo com Antunes (2002, p.14), "a aprendizagem é tão importante quanto o desenvolvimento social e o jogo constitui uma ferramenta pedagógica ao mesmo tempo promotora do desenvolvimento cognitivo e do desenvolvimento social". Por ser parte intrínseca do ser humano, o lúdico não deve ser utilizado somente na pré-escola, pois também permite a motivação para a aprendizagem em crianças maiores, em adolescentes e até mesmo em adultos ou idosos. As actividades lúdicas, se bem preparadas dentro do contexto que o professor quer trabalhar, estimularão a vontade do aluno e propiciarão a aprendizagem. De acordo com Harmer (1991), "parece sensato sugerir que a motivação que os alunos trazem para a sala de aula é o único maior factor que afecta o seu sucesso (...) mas se os alunos não vierem com esta motivação, então é trabalho do professor induzila" (Silvers 2005, p.220). Segundo Pessanha (2001, p.36), a actividade lúdica "é fácil de identificar e difícil de definir". Durante algum tempo foi atribuída uma conotação negativa a este tipo de actividade, pelo facto de ter sido considerada muitas vezes como antagónica do trabalho, o que não favoreceu o seu estudo por investigadores. Actualmente, porém, o seu papel é reconhecido como essencial em muitos aspectos do domínio cognitivo, social e afectivo do desenvolvimento da criança.

Existem descrições da utilização de actividades lúdicas na prática pedagógica na Grécia e na Roma antiga. Contudo, de acordo com Lopes (2007) é essencialmente na segunda metade do século XX, que emergem as teorias de maior expressão para fundamentar a utilização de actividades lúdicas. A maioria dos autores destaca estas actividades como elementos motivadores e facilitadores do processo de ensino e aprendizagem. Defendem, ainda, que o propósito das actividades lúdicas não se resume apenas a facilitar que o aluno memorize o assunto abordado, mas sim a induzi-lo ao raciocínio, à reflexão, ao pensamento e, consequentemente, à (re)construção do seu conhecimento.

De acordo com Teixeira (1995), existem vários motivos para a utilização de actividades lúdicas nas práticas pedagógicas, entre eles: (i) os recursos lúdicos correspondem naturalmente a uma satisfação interior, pois o ser humano apresenta uma tendência lúdica; (ii) o prazer e o esforço espontâneo são elementos fundamentais na constituição das actividades lúdicas; (iii) as actividades lúdicas mobilizam esquemas mentais, estimulando o pensamento e o senso crítico; e (iv) as actividades integram e accionam as esferas motoras, cognitivas e afectiva dos seres humanos.

Apesar de apresentarem diferentes pontos de vista, psicólogos com forte influência na pedagogia, como Jean Piaget, Henri Wallon e Lev Vygotsky, frisaram categoricamente a importância que os métodos lúdicos proporcionam à educação de crianças, adolescentes e adultos. Referem, por exemplo, que nos momentos de maior descontracção e desinibição, facultados pelas actividades lúdicas, as pessoas descontraem-se, o que proporciona maior aproximação, uma melhoria na integração e na interacção do grupo, facilitando a aprendizagem (Negrine 2001). Deve-se salientar que para Vigotsky (2002), o aluno exerce um papel activo no processo de aprendizagem, por apresentar condições de relacionar o novo conteúdo aos seus conhecimentos prévios, e o professor torna-se o responsável por criar zonas de desenvolvimento proximal, ou seja, proporciona condições e situações para que o aluno transforme e desenvolva na sua mente um processo cognitivo mais significativo.

Outra característica associada às actividades lúdico-práticas é o seu carácter desafiante. O desafio motiva o aluno a conhecer as suas potencialidades e as suas possibilidades de superação de dificuldades, na procura do "triunfo", adquirindo auto-estima e melhorando as suas expectativas de auto-eficácia. Assim sendo, as actividades lúdico-práticas podem ser consideradas estimulantes, despertando um real 
interesse dos alunos para com termos e conceitos específicos da Geologia.

É possível considerar um vasto leque de actividades lúdico-práticas: resolução de enigmas, dinâmicas de integração grupal, actividades rítmicas, trabalhos de recorte e colagem, exercícios de expressão dramática, jogos, entre outras possibilidades. Mais importante do que o tipo de actividade, no entanto, é a forma como esta é orientada, vivenciada, e como é percepcionada, ou seja, se são bem entendidas as razões por que está a ser realizada. As actividades lúdico-práticas que têm tido mais relevo no processo de ensino e aprendizagem, pela qualidade intrínseca que possuem de despertar motivação, são os jogos.

No presente estudo é adoptada a definição de jogo de Kishimoto (1996), que aponta para três níveis de diferenciação:

i) jogo é o resultado de um sistema linguístico, isto é, o sentido do jogo depende da linguagem e do contexto social. A noção de jogo não remete à língua particular de uma ciência, mas a um uso quotidiano. Assim, o essencial não é obedecer à lógica de uma designação científica dos fenómenos e sim, respeitar o uso quotidiano e social da linguagem, pressupondo interpretações e projecções sociais;

ii) jogo é um sistema de regras, ou seja em qualquer jogo é possível identificar uma estrutura sequencial que especifica a sua modalidade. Estas estruturas sequenciais de regras permitem uma grande relação com a situação lúdica, ou seja, quando alguém joga, está a executar regras do jogo, mas ao mesmo tempo, desenvolve uma actividade lúdica (prazer). Estas regras podem ser explícitas ou implícitas. No primeiro caso, são as regras definidas em consenso pelo grupo, comunidade ou sociedade que joga ou brinca; no segundo caso, são as regras implícitas em cada actividade;

iii) jogo é um objecto, por exemplo, um pião (de madeira, casca de fruta, ou de plástico), que representa o objecto a utilizar numa actividade.

Em virtude das numerosas classificações existentes na literatura, no âmbito do presente estudo, procurou-se encontrar uma classificação para a diversidade de jogos que contemplasse os aspectos didáctico-metodológicos do jogo. Gran- do (1995) propõe uma classificação muito útil das finalidades que o jogo pode assumir no ambiente educacional:

- jogos de azar, ou jogos de sorte, no qual o jogador conta apenas com a "sorte", ou seja, depende de certas probabilidades para vencer. Não há um meio de o jogador modificar ou intervir no resultado ou na resolução do jogo;

- jogos quebra-cabeça: geralmente, são jogos individuais, cuja solução é desconhecida pelo jogador;

- jogos de estratégia ou de construção de conceitos: são aqueles que não dependem da sorte, mas das decisões tomadas pelo jogador para vencer o jogo, ou seja, das estratégias adoptadas por ele no decorrer de uma partida;

- jogos de fixaçãa de conceitos: como o nome sugere, o seu objectivo é "fixar conceitos". São os mais utilizados nas escolas, seja em substituição de listas de exercícios ou mesmo para aplicação de conceitos previamente adquiridos;

- jogos computacionais: são aqueles que utilizam o computador na execução e aplicação; actualmente despertam maior interesse em crianças e adolescentes;

- jogos pedagógicos: são aqueles votados a favorecer o processo de ensino e aprendizagem e possuem valor pedagógico agregado; é, por isso, possível incluir neste tipo de jogos todas as categorias supracitadas.

Segundo Miranda (2001) a relevância da inclusão de jogos nos processos educativos em contexto de sala de aula está directamente relacionada com cinco fenómenos de aprendizagem: (i) cognição (desenvolvimento da inteligência e da personalidade, fundamentais para a construção de conhecimentos); (ii) afeição (desenvolvimento da sensibilidade e da estima e actuação no sentido de estreitar laços de amizade e afectividade); (iii) socialização (simulação de vida em grupo); (iv) motivação (envolvimento da acção, do desafio e mobilização da curiosidade); e (v) criatividade (exercício de imaginação).

Em consonância com o anteriormente referido, conclui-se que as actividades lúdico-práticas constituem um importante instrumento de trabalho quando o mediador as explora no sentido de desenvolver competências e promover a motivação dos 
alunos. O lúdico é integrador de várias dimensões como, por exemplo, a afectividade e a colaboração entre pares. Assim, contribui para a motivação e o desenvolvimento cognitivo dos alunos, estimulando a interacção aluno-aluno e aluno-professor.

\section{Modelos 3D da Tectónica de Placas e o Jogo "O Ciclo das Rochas"}

O desenvolvimento do estudo iniciou-se com a definição dos temas geológicos a abordar para a implementação das actividades lúdico-práticas, estando a escolha intimamente relacionada com a definição do público-alvo. A escolha recaiu sobre os temas "Tectónica de Placas" e "Ciclo das Rochas". Pressupõe-se que os temas escolhidos englobam a compreensão de diversos processos geológicos, permitindo a relação e interligação de um vasto conjunto de conceitos geológicos, abordados no ensino obrigatório português. Após definição dos temas geológicos a abordar e selecção dos protótipos, a elaboração das actividades recaiu na adaptação de duas actividades lúdico-práticas: (i) Actividade 1 - Modelos 3D da Tectónica de Placas; (ii) Actividade 2 - Jogo "O Ciclo das Rochas".

O desenvolvimento das actividades pressupõe a intervenção de um aluno ou grupo de alunos num ambiente colaborativo, mediante a actividade lúdico-prática a utilizar.

\section{Actividade 1: Modelos 3D da Tectónica de Placas (figs. 2, 3, 4 e 5)}

A actividade lúdico-prática 1 teve por base os modelos tridimensionais apresentados no CD-ROM Explore Plate Tectonics (Gary B. Lewis e Tau Rho Alpha 2003). O CD-ROM foi adquirido no endereço electrónico da The Geological Society of America ${ }^{1}$, A autorização para adaptação dos modelos foi solicitada e consentida.

Da actividade lúdico-prática fazem parte os seguintes materiais: modelo da expansão do fundo oceânico, composto por duas folhas (parte lateral (Fig. 2) e parte inferior (Fig. 3) do modelo); modelo de subducção, composto por duas folhas (parte superior (Fig. 4) e parte inferior (Fig. 5)); tesoura; e cola. De salientar que os modelos foram impressos em papel de $160 \mathrm{~g} / \mathrm{m}^{2}$.

\footnotetext{
$\overline{1}$ (http://rock.geosociety.org/bookstore/default.asp?olD $=0 \&$ catlD $=48$, acedido em Dezembro de 2007).
}

A actividade lúdico-prática, Modelos 3D da Tectónica de Placas, perspectiva a construção de um de dois modelos a três dimensões (modelo da expansão do fundo oceânico e modelo de subducção) por aluno. No início da actividade, o professor fornece aos alunos instruções dos diferentes passos a ter em consideração no recorte e na colagem das diferentes peças de cada modelo. A duração da actividade é de aproximadamente de 60 minutos. No final, os alunos conseguem visualizar de uma forma dinâmica diferentes tipos de movimento de possíveis placas litosféricas (limite divergente entre placas de crusta oceânica e limite convergente entre uma placa oceânica e uma placa continental).

Os alunos ao desenvolverem a actividade lúdico-prática deverão ser capazes de distinguir entre zona de subducção e zona de expansão.

\section{Actividade 2: Jogo - 0 Ciclo das Rochas}

A actividade desenvolvida teve por base o jogo apresentado no endereço electrónico: http://edweb. sdsu.edu/courses/edtec670/Cardboard/Board/ R/ RockCycleRace/index.htm (acedido em Dezembro de 2007), elaborado por Gulcin Cirik, Dave Comstock, Amy Pastor e Elaine Winfrey. Na página inicial do site (http://edweb.sdsu.edu/courses/edtec670/ Cardboard/BoardTOC.html), contendo mais de uma centena de jogos, pode ler-se uma mensagem informando que estes não se encontram à venda e é incentivada a criação de versões pessoais que os autores autorizarão sempre.

Da actividade lúdico-prática 2 fazem parte os seguintes objectos: tabuleiro de jogo (Figs. 6), tamanho $50 \times 50 \mathrm{~cm}$; três peões de jogo que representam rochas; um dado; um tríptico com as regras; e uma ampulheta de 30 segundos; três conjuntos de Cartões de Perguntas: Magmáticas, Sedimentares e Metamórficas.

No desenrolar do Jogo - O Ciclo das Rochas, os alunos percorrem caminhos que reproduzem os processos do ciclo das rochas, fazendo depender o movimento das suas peças na resposta correcta a um conjunto de questões. Assim, os alunos avançam no tabuleiro de jogo, mediante uma estratégia adoptada. Os jogadores são motivados a aumentar o seu conhecimento do ciclo das rochas para vencer. Deve proceder-se à formação de 3 equipas de jogadores, sendo que em cada equipa deve ser definido um portavoz. O jogo pode ser colocado em prática durante aproximadamente 50 minutos (Fig. 7 e 8). Os alunos 


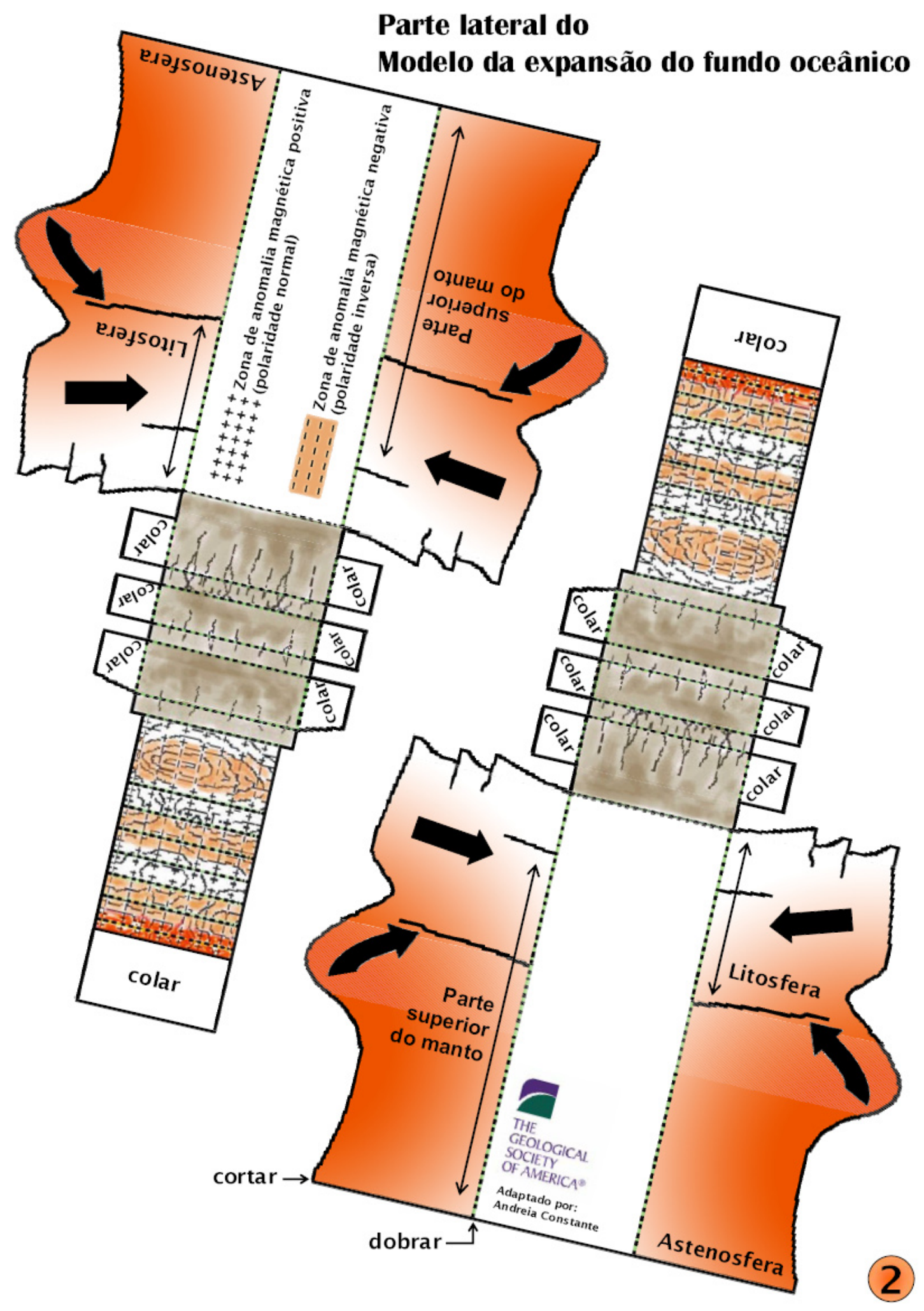

Figura 2 - Folha um do modelo da expansão do fundo oceânico da actividade 1 


\section{Página deixada em branco para construção do modelo}




\section{Parte inferior do}

\section{Modelo da expansão do fundo oceânico}

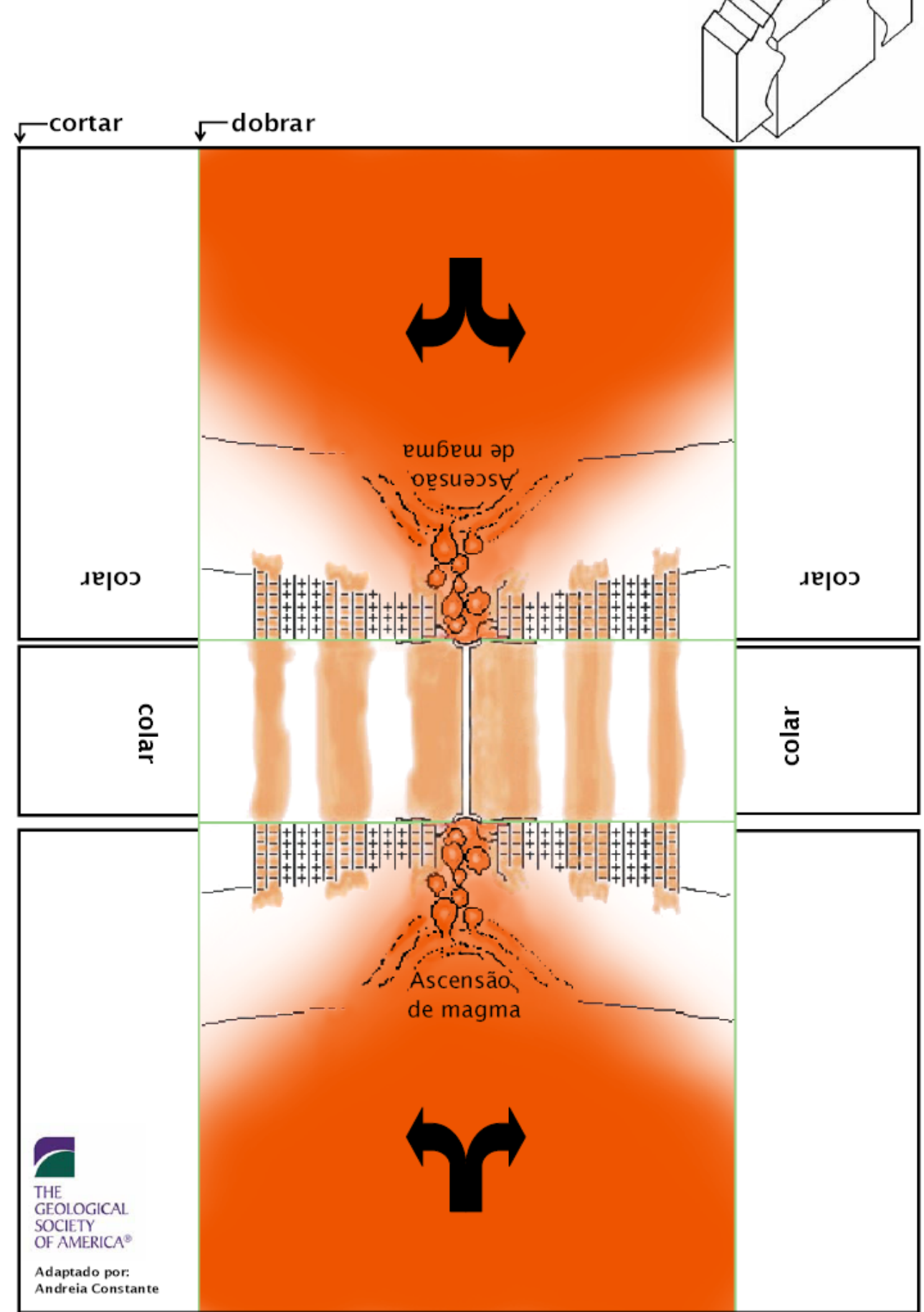

Figura 3 - Folha dois do modelo da expansão do fundo oceânico da actividade 1 


\section{Página deixada em branco para construção do modelo}




\section{Parte superior do}

\section{Modelo de Subducção}

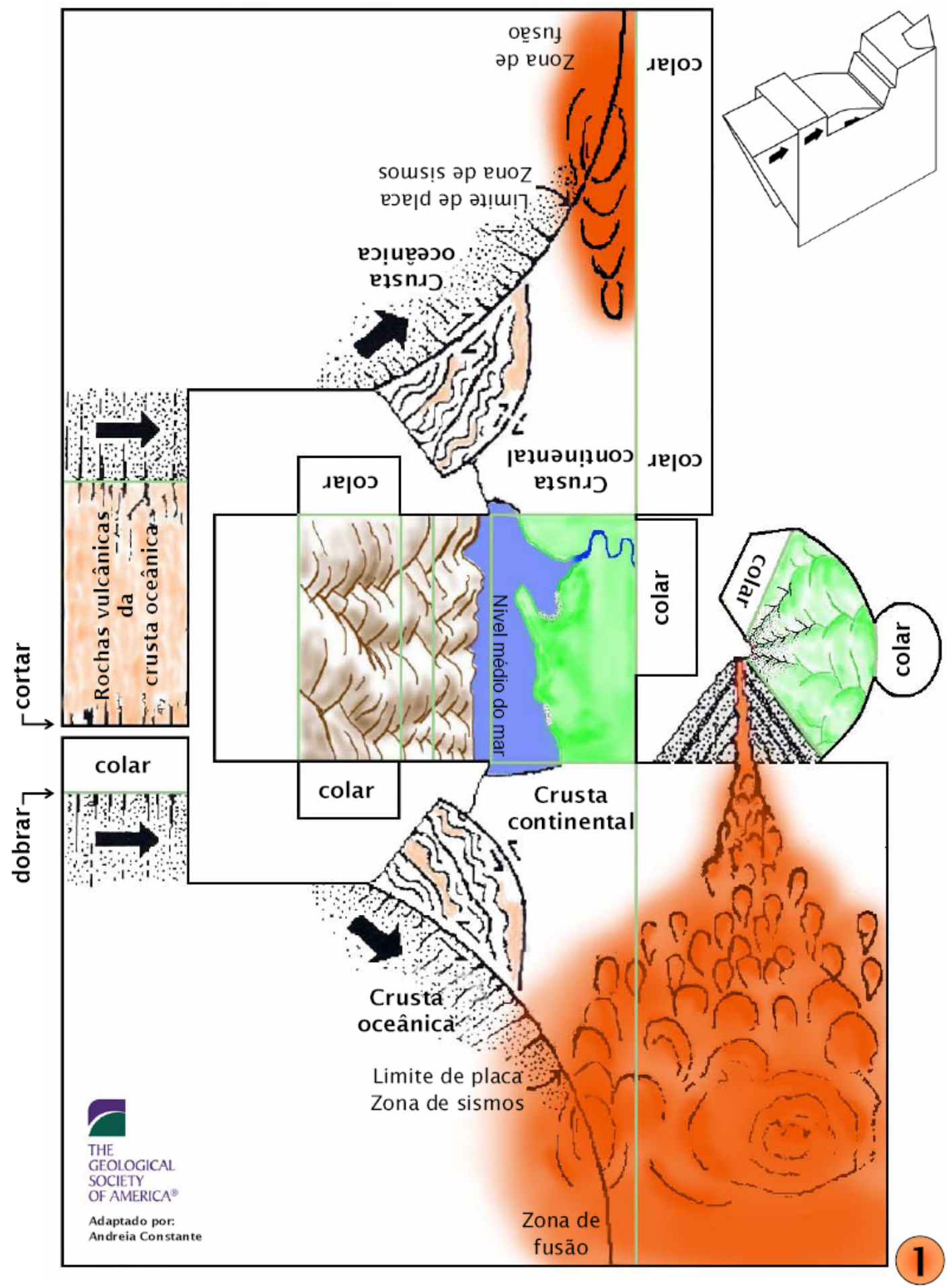

Figura 4 - Folha um do modelo de subducção da actividade 1 


\section{Página deixada em branco para construção do modelo}




\section{Parte inferior do}

\section{Modelo de Subducção}



Figura $\mathbf{5}$ - Folha dois do modelo de subducção da actividade 1 


\section{Página deixada em branco para construção do modelo}




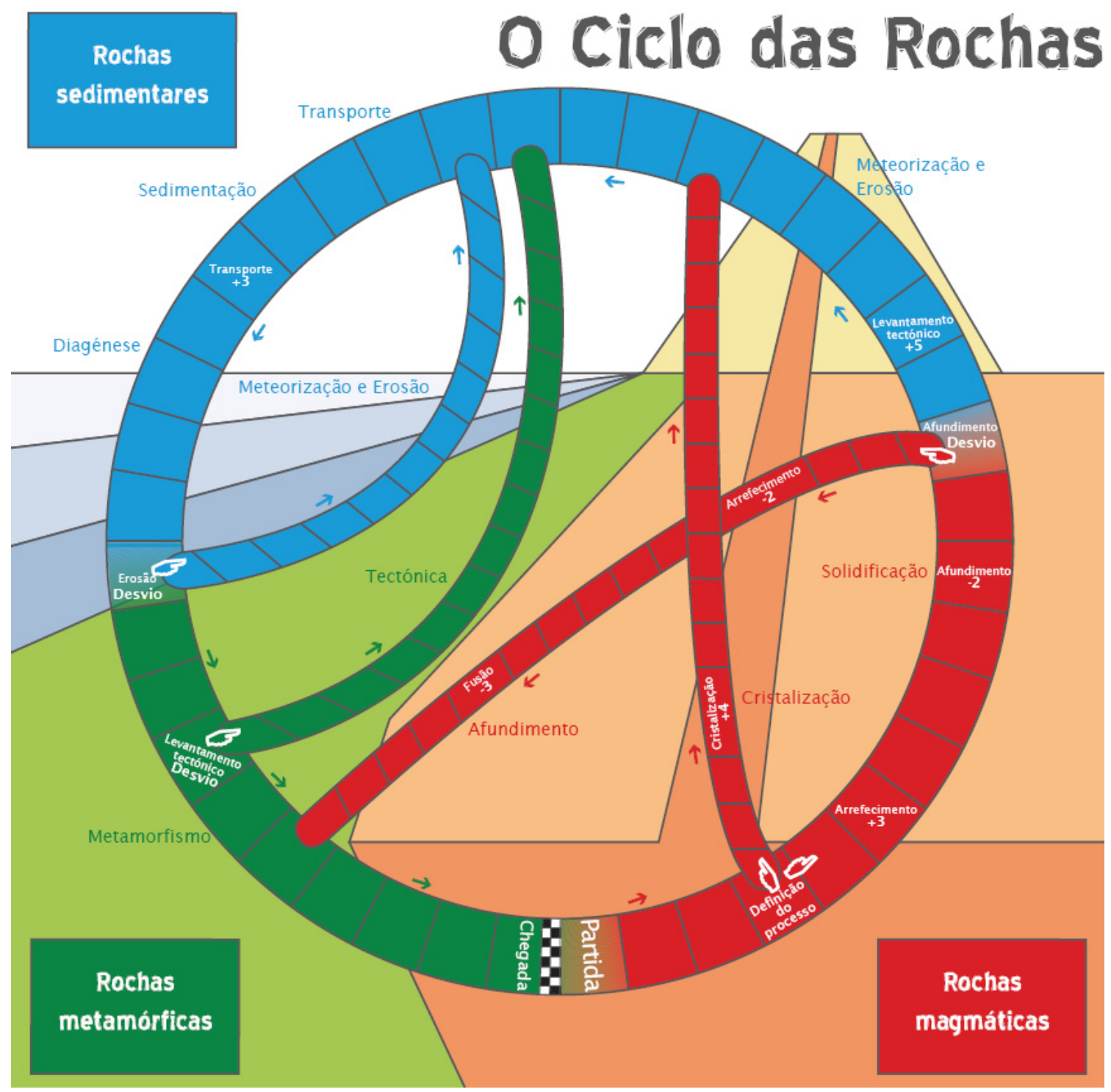

Figura 6 -Tabuleiro do jogo da actividade 2

precisarão aproximadamente de dez minutos para preparar ojogo e de cinco minutos para arrumá-lo. $\mathrm{O}$ jogo em si demora cerca de 30 a 35 minutos.

Os alunos ao desenvolverem a actividade lúdicoprática, Jogo - O Ciclo das Rochas, serão capazes de identificar um conjunto de factores e processos relativos à formação, tipos e ciclo das rochas. Estes conteúdos programáticos foram anteriormente abordados nas aulas de Ciências Naturais, permitindo assim reforçar a sua compreensão sobre os factores e processos mencionados.

\section{Metodologia de Investigação}

$\mathrm{Na}$ presente investigação, recorreu-se a uma amostra por conveniência, que recaiu sobre alunos portugueses a frequentar, no ano lectivo de 2007/2008, a disciplina de Ciências Naturais, numa escola pública da Região Norte de Portugal. A amostra foi constituída por 71 alunos entre 12 e 14 anos, distribuídos por três turmas. Relativamente ao género, $48 \%$ eram do sexo masculino.

A opção metodológica seleccionada para a operacionalização do desenvolvimento deste estudo teve como propósito elaborar produtos escolares para serem utilizados com determinados fins e de acordo com especificações pormenorizadas como, por exemplo, materiais de aprendizagem. $\mathrm{Na}$ presente investigação recorreu-se à triangulação metodológica, o que implica várias técnicas de 


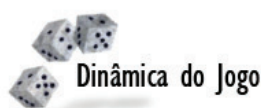

O Ciclo das Rochas é um jogo de tabuleiro em que os jogadores se movem ao longo do percurso do ciclo das rochas. Todos os jogadores começam na "Partida" e o primeiro a atingir a "Chegada" ganha o jogo. O percurso de jogo está dividido em casas. Em algumas casas os jogadores podem escolher a direcção a tomar, encontrar desvios e/ ou obstáculos.

Os jogadores só avança ao longo do tabuleiro respondendo, correctamente, às questões que constam dos cartões.

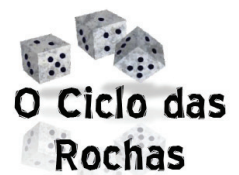

Regras do Jogo

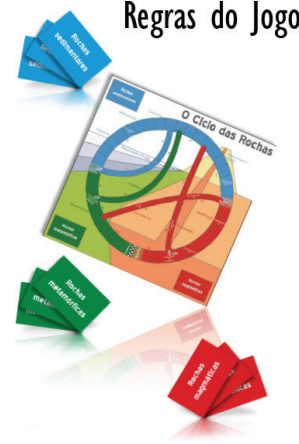

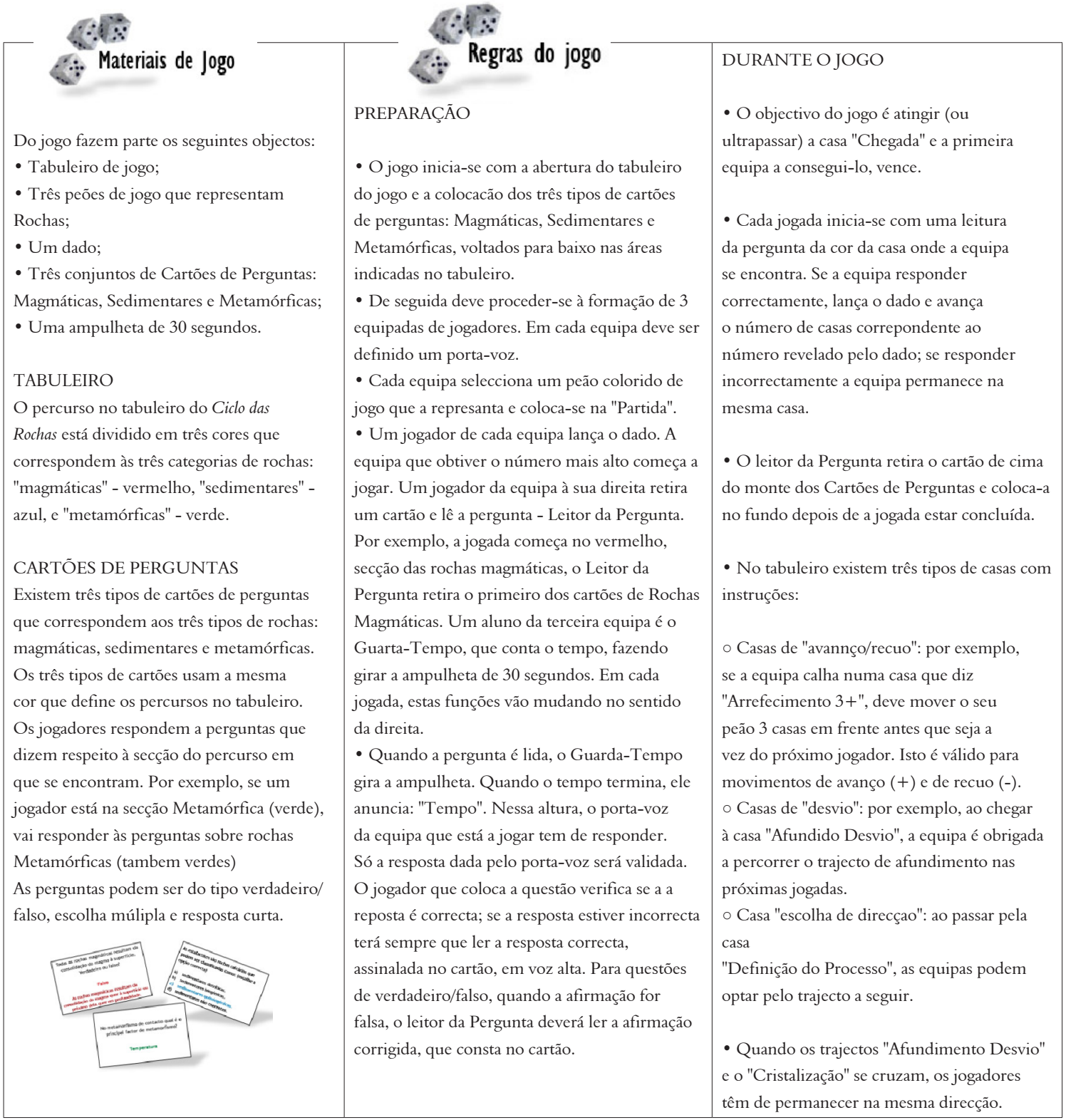

Figura 7 - Lado externo e interno do triptico de jogo da actividade 2 
recolha de dados, cuidadosamente seleccionadas e aplicadas (ver quadro 3).

A triangulação metodológica contribuiu para assegurar a fiabilidade dos resultados. Não obstante, os instrumentos aplicados foram alvo de validação por especialistas na área. Os instrumentos referidos no quadro 3 foram aplicados, ou preenchidos, no fim da realização de cada uma das actividades. O professor aplicador foi a investigadora (primeira

Quadro 3 - Métodos, técnicas e instrumentos utilizados no estudo

\begin{tabular}{|c|c|c|c|c|}
\hline Método & $\begin{array}{c}\text { Técnica de } \\
\text { recolha dedados }\end{array}$ & Instrumento & $\begin{array}{c}\text { Técnica de } \\
\text { análise de dados }\end{array}$ & Respondente \\
\hline Quantitativo & Inquérito & Questionários & $\begin{array}{c}\text { Análise } \\
\text { estatística }\end{array}$ & Alunos \\
\hline Qualitativo & $\begin{array}{c}\text { Observação } \\
\text { participante }\end{array}$ & $\begin{array}{c}\text { Relatório de } \\
\text { observação }\end{array}$ & $\begin{array}{c}\text { Análise de } \\
\text { conteúdo }\end{array}$ & $\begin{array}{c}\text { Professor } \\
\text { aplicador }\end{array}$ \\
\hline Qualitativo & $\begin{array}{c}\text { Observação não } \\
\text { participante }\end{array}$ & $\begin{array}{c}\text { Relatório de } \\
\text { observação }\end{array}$ & $\begin{array}{c}\text { Análise de } \\
\text { conteúdo }\end{array}$ & $\begin{array}{c}\text { Professor } \\
\text { observador }\end{array}$ \\
\hline
\end{tabular}

autora do artigo) e o professor observador era professor de Ciências Naturais no estabelecimento de ensino onde foram implementadas as actividades. Cada uma das actividades foi aplicada uma vez em cada turma. As turmas foram divididas em blocos de cerca de 12 alunos, permitindo uma facilitada aplicação das actividades. Esta divisão é determinada pelo Ministério de Educação Português, não tendo sido imposta pelo presente estudo.

Para aferir a opinião dos alunos sobre as actividades lúdico-práticas aplicadas na investigação, elaboraram-se dois questionários, um para cada actividade, com a preocupação que as questões fossem claras, sem ambiguidades e adaptadas à faixa etária dos inquiridos. Os questionários foram administrados nas aulas correspondentes ao final da realização de cada actividade lúdico-prática.

Os questionários contemplavam cinco questões de resposta fechada, que pretenderam avaliar a actividade a partir das seguintes categorias: motivação e participação do aluno, mediação do professor aplicador, dificuldade da actividade e compreensão da finalidade da tarefa. A única questão aberta tentou identificar a importância que os alunos-alvo atribuem à realização de actividades lúdico-práticas no seu processo de aprendizagem na disciplina de Ciências Naturais.

$\mathrm{Na}$ implementação do estudo foram realizados dois tipos de observação (Spradley 1980): (i) observação participante do tipo activo, com um elevado grau de envolvimento, onde o professor aplicador, para além da sua presença, esteve envolvido nos acontecimentos e fez o seu registo, imediatamente após as aulas terem tido lugar; (ii) observação não participante, realizada pelo professor observador que, durante a concretização das actividades, efectuou o registo de informações.

Para a orientação das observações e registro de notas construíram-se instrumentos específicos relatórios de observação. Os documentos incluíam um conjunto de pontos orientadores que visavam recolher as seguintes informações acerca do desenvolvimento da actividade lúdico-prática: aspectos referentes à reacção dos alunos (motivação, participação e comportamento), às metodologias de trabalho e às dificuldades sentidas pelo professor aplicador e pelos alunos.

Os relatórios foram respondidos individualmente por cada professor interveniente durante a actividade (observador) ou após (aplicador).

\section{Resultados e Discussão}

No presente estudo, os dados dos questionários foram tratados estatisticamente, embora nas questões abertas se tenha recorrido à análise de conteúdo com respectiva categorização e codificação. Para as respostas às questões fechadas procedeu-se a uma análise estatística descritiva, por meio do software Statistical Package for Social Science (SPSS - versão 17.0). Os relatórios dos observadores foram alvo de análise de conteúdo e respectiva categorização de respostas. Esta análise permitiu extrair informações pormenorizadas sobre a forma como decorreu a implementação de cada uma das actividades lúdicopráticas.

A apresentação dos resultados neste artigo resume-se à análise conjunta dos resultados, isto é das duas actividades em simultâneo. A apresentação é esclarecedora e, ao mesmo tempo, sintética, uma vez que foi possível comparar as mesmas dimensões nas duas actividades lúdico-práticas.

No que se refere aos questionários, a análise conjunta das questões fechadas permitiu constatar que os alunos manifestaram-se muito motivados perante a realização de actividades lúdico-práticas, 


\section{Questões dos cartões "Rocha Magmática"}

\begin{tabular}{|c|c|}
\hline $\begin{array}{l}\text { O granito é uma rocha magmática } \\
\text { plutónica. Verdadeiro ou falso? }\end{array}$ & $\begin{array}{c}\text { Todas as rochas magmáticas resultam } \\
\text { da consolidação do magma à } \\
\text { superfície. Verdadeiro ou falso? } \\
\text { Falso }\end{array}$ \\
\hline Verdadeiro & $\begin{array}{l}\text { As rochas magmáticas resultam } \\
\text { da consolidação do magma quer à } \\
\text { superfície ou próximo dela quer em } \\
\text { profundidade. }\end{array}$ \\
\hline $\begin{array}{c}\text { As rochas plutónicas são constituídas } \\
\text { por minerais não visíveis à vista } \\
\text { desarmada. Verdadeiro ou falso? } \\
\text { Falso }\end{array}$ & $\begin{array}{l}\text { O basalto consolida à superfície ou } \\
\text { próximo dela. Verdadeiro ou falso? }\end{array}$ \\
\hline $\begin{array}{c}\text { As rochas plutónicas são constituídas } \\
\text { por mineiras cristalizados visíveis à } \\
\text { vista desarmada. }\end{array}$ & Verdadeiro \\
\hline $\begin{array}{c}\text { O basalto é uma rocha de cor } \\
\text { escura constituída na sua totalidade } \\
\text { por elementos bem visíveis à vista } \\
\text { desarmada. Verdadeiro ou falso? } \\
\text { Falso }\end{array}$ & $\begin{array}{l}\text { O arrefecimento lento dos magmas } \\
\text { origina rochas com minerais } \\
\text { desenvolvidos. Verdadeiro ou falso? }\end{array}$ \\
\hline $\begin{array}{l}\text { basalto é uma rocha de cor escura } \\
\text { podendo ser constituída apenas } \\
\text { por alguns minerais visíveis à vista } \\
\text { desarmada. }\end{array}$ & Verdadeiro \\
\hline $\begin{array}{c}\text { As rochas vulcânicas formam-se no } \\
\text { interior da Terra. Verdadeiro ou falso? } \\
\text { Falso }\end{array}$ & $\begin{array}{l}\text { Existem dois tipos de rochas } \\
\text { magmáticas, dependendo do local de } \\
\text { solidificação. Verdadeiro ou falso? }\end{array}$ \\
\hline $\begin{array}{l}\text { As rochas vulcânicas formam-se à } \\
\text { superfície terrestre ou próximo dela. }\end{array}$ & Verdadeiro \\
\hline
\end{tabular}




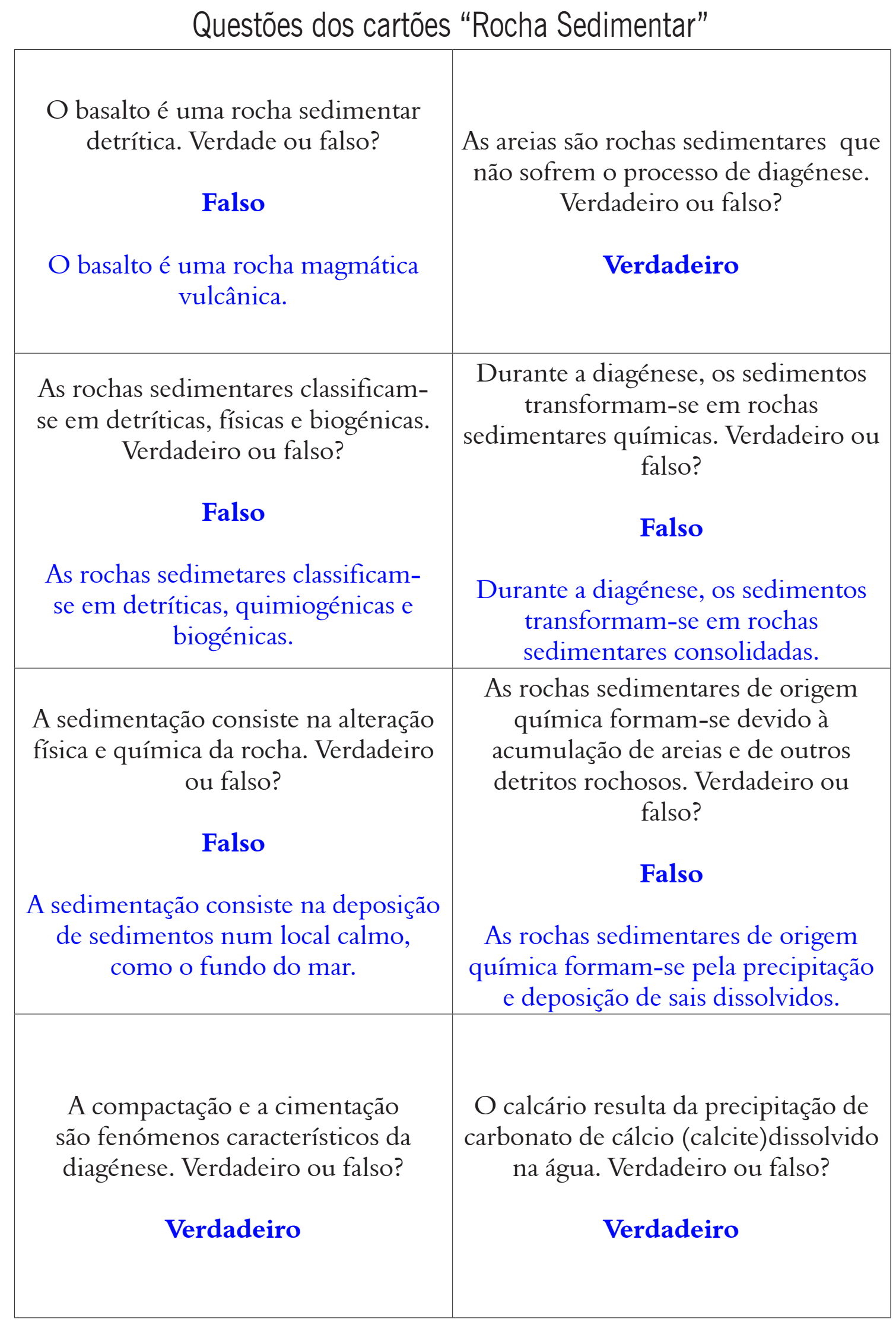




\section{Questões dos cartões "Rocha Metamórfica"}

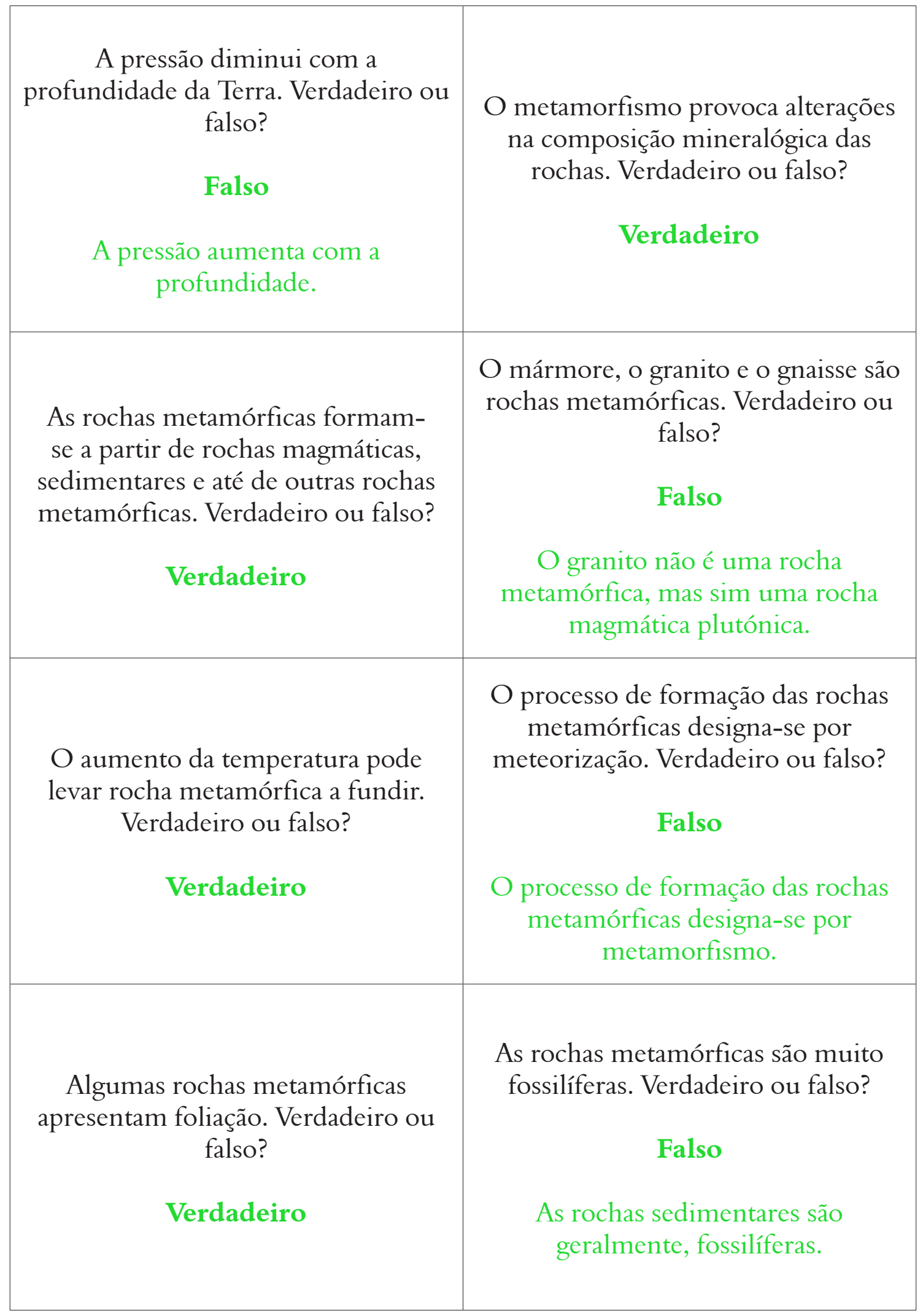


no contexto sala de aula, considerando que a mediação do professor aplicador foi esclarecedora. Estes dados permitem estabelecer uma relação entre a motivação manifestada e a participação activa dos alunos na concretização das actividades lúdicopráticas aplicadas. Relativamente, à viabilidade das actividades propostas, um número significativo de alunos considerou que as mesmas eram fáceis de realizar. Por último, a grande maioria dos alunos manifestou ter compreendido o objectivo proposto para ambas as actividades. As respostas à questãoaberta dos questionários - "De que forma é que este tipo de actividades poderá ajudar-te na aprendizagem da disciplina de Ciências Naturais?” - sofreram uma prévia análise de conteúdo com categorização das mesmas. O estudo das respostas obtidas permite afirmar que a maioria dos alunos considerou que as actividades lúdico-práticas são um auxílio na compreensão de conteúdos programáticos e a sua realização desempenha um papel motivador fulcral na aprendizagem. A sustentar esta conclusão expõem-se alguns exemplos do que foi escrito pelos inquiridos: "...ajuda a compreender melhor a matéria”; “...ajuda a compreender coisas que em palavras não entendo”; “... porque percebo melhor a matéria de uma forma mais divertida e esclarecedora"; “... fico mais entusiasmado para a matéria”; “... ajuda os alunos a interessarem-se mais pelas aulas"; "...ajuda os alunos a estarem com mais atenção, quando se trata de actividades lúdicas"; “... assim as aulas não são tão aborrecidas"; e “...os alunos ficam mais motivados e aprendem melhor". Acrescente-se que, nos textos construídos nas respostas à questão 6 , os alunos nunca referiram algum aspecto menos positivo relativamente às actividades lúdico-práticas implementadas.

A interpretação dos dados da análise do questionário torna óbvio o impacte extremamente positivo que estas estratégias exerceram nos alunos.

Nesta investigação, o recurso à observação possibilitou o testemunhar das reacções, comentários, dúvidas, preocupações e ideias dos intervenientes (alunos) sobre toda a problemática em estudo, que foram descritos, no final de cada aplicação das actividades lúdico-práticas, na forma de relatório de observação. Os relatórios, doze no total, foram preenchidos pelos docentes envolvidos: o professor aplicador (observação participante) e o professor observador (observação não participante).

Os resultados, da análise de conteúdo realizada, foram sujeitos a prévia categorização após estudo detalhado dos relatórios do professor observador e do professor aplicador. Recorde-se que os relatórios de observação eram orientados.

Segundo os professores envolvidos na concretização da actividade lúdico-prática 1 , os alunos manifestaram entusiasmo e interesse na realização da mesma, o que se reflectiu numa participação activa. A principal dificuldade identificada nos alunos prendeu-se com a montagem de um dos modelos (Modelo da expansão do fundo oceânico), embora esta tenha sido ultrapassada com a intervenção do professor aplicador.

Relativamente à actividade 2 , tal como na actividade anterior, os alunos envolveram-se activamente, demonstrando interesse e satisfação ao jogar. A competitividade gerada revelou-se extremamente motivadora. Verificou-se que, para além de a actividade lúdico-prática ter servido como um recurso didáctico para consolidar os conteúdos curriculares, para o professor aplicador funcionou, também, como um instrumento de avaliação formativa. Constatou-se que a dinâmica gerada nos diferentes turnos foi muito diversa, o que se pode explicar pela variável "dimensão do grupo". De facto, o número de alunos foi um factor preponderante para o sucesso desta actividade, uma vez que decorreu de forma mais ordenada quando as equipas não ultrapassavam os quatro elementos. Uma outra variável a considerar relaciona-se com a personalidade e singularidade dos indivíduos que apresentam formas distintas de participação (reflectidas em manifestações de sentimentos tão variados como alegria, nervosismo, euforia, ansiedade e mesmo decepção com os resultados obtidos).

Após reflexão das respostas obtidas na aplicação das duas actividades, procedeu-se elaboração à de um quadro síntese. Para a sua realização, predefiniram-se cinco categorias: Motivação dos alunos, Participação dos alunos, Autonomia dos alunos, Mediação do professor aplicador e Material.

O quadro 4 sintetiza os resultados obtidos para cada dimensão referida numa escala qualitativa: fraco, razoável, bom, muito bom. Esta escala emerge de uma análise pormenorizada das respostas obtidas nos diferentes instrumentos de avaliação.

A análise do quadro 4 permite concluir que as actividades lúdico-práticas propostas neste estudo motivaram, desenvolveram a sua autonomia e despertaram a sua participação activa. Os bons resultados alcançados devem-se, também, à mediação do professor aplicador, que teve um papel prepon- 
Quadro 4 - Análise conjunta dos resultados das actividades lúdico-práticas.

\begin{tabular}{|l|c|c|}
\hline Categorias & Actividade 1 & Actividade 2 \\
\hline Motivação dos alunos & Muito bom & Muito bom \\
\hline Participação dos alunos & Bom & Bom \\
\hline Autonomia dos alunos & Bom & Muito bom \\
\hline Mediação do PA & Bom & Muito bom \\
\hline Material & Bom & Bom \\
\hline
\end{tabular}

derante na contextualização, explicação e orientação das actividades implementadas, assim como à qualidade dos materiais utilizados.

\section{Conclusões e implicações educacionais}

Entendidas como elementos facilitadores no processo de ensino e aprendizagem de conceitos e processos da Geologia, a presente investigação teve como principal objectivo a avaliação do impacto das actividades lúdico-práticas, nomeadamente, através da análise do nível de motivação, autonomia e participação dos alunos. Aproveitando o incomensurável potencial da Internet, utilizaram-se duas actividades que serviram de base a este trabalho: um modelo tridimensional da Tectónica de Placas e um jogo sobre o Ciclo das Rochas. Ambas foram adaptadas e aplicadas a alunos com idade entre os 12 e os 14 anos.

Confirmando o que alguns autores defendem (Miranda 2001, Negrine 2001, Grando 2000), as actividades lúdico-práticas estão imbuídas de uma componente fortemente motivadora e desafiante, tendo sido perceptível nos alunos o desejo de as realizarem e o entusiasmo com que se envolveram. As opiniões escritas dos alunos desta investigação apontam também o seu valor cognitivo, já que atestam que os ajudou a compreender conteúdos curriculares, o que vai ao encontro do já afirmado por Teixeira (1995) e de Negrine (2001). Por outro, as actividades lúdico-práticas que envolvem a formação de grupos obrigam os alunos a um trabalho colaborativo com os pares. Isto potencia uma proximidade maior entre os estudantes, que foi notória durante a realização do jogo. As actividades lúdico-práticas cumpriram, assim, não só a sua função pedagógica como complemento motivacional, estimulando a aprendizagem por parte dos alunos e auxiliando a tarefa do professor, mas também desempenharam um papel socializador.

Embora esta investigação tenha evidenciado um impacto positivo junto dos alunos participantes, é necessário continuar a potenciar a implementação de actividades práticas que permitam valorizar o papel motivacional das actividades lúdicas e se constituam como possuidoras de forte valor didáctico.

\section{Referências Bibliográficas}

Antunes C. 2002. Vygotsky, quem diria?! Em minha sala de aula. Rio de Janeiro: Vozes.

Balancho M., Coelho M. 2004. Motivar os Alunos. Criatividade na relação pedagógica: conceitos e práticas. 3 ed. Lisboa: Texto Editores.

Caamaño A. 2003. Los trabajos prácticos en Ciencias. In: Caamaño A., Oñorbe A., Pedrinaci E., Pro A., Aleixandre M. P. eds. Enseñar ciências. Barcelona: Graó. p. 95-118.

Christie J., Johnsen E. 1983. The role of play in social-intellectual development. Rev. Educ. Rs. 53:93-115.

Constante A. 2009. Actividades lúdico-práticas no Ensino da Geologia: um estudo com alunos do $7^{\circ}$ ano de escolaridade. Porto: Fac. Ciências, Univ. Porto. (Dissert. de Mestrado).

Grando R. 1995. O jogo e suas possibilidades metodológicas no processo ensino-aprendizagem da matemática. Campinas: Univ. Est. Campinas. (Dissert. Mestr.).

Grando R. 2000. O conhecimento matemático e o uso de jogos na sala de aula. Campinas: Univ. Est. Campinas. (Tese Dout.).

Harmer J. 1991. The practice of English language teaching. London: Longman.

Hodson D. 1993. Rethinking old ways: Towards a more critical approach to practical work in school science. Studies in Science Education, 22: 85-142.

Hodson D. 1988. Experiments in science and science teaching. Educational Philosophy and Theory, 20(2):53-66.

Kishimoto T. 1996. Jogo, Brinquedo, Brincadeira e Educação. São Paulo: Cortez.

Leite L. 2001. Contributos para uma utilização mais fundamentada do trabalho laboratorial no ensino das Ciências. In: Caetano H., Santos M. P. eds. Cadernos Didácticos de Ciências Lisboa: Ministério da Educação, Departamento de Educação Básica. vol. 1, p. 79-97.

Lewis G., Alpha T.R. 2003. Explore plate tectonics. Geol. Soc. Am. (CD-ROM). URL: http://rock.geosociety.org/bookstore/default.asp?oID $=0 \&$ catID $=48$. Acesso 26.01.2011

Lopes O. 2007. Jogo "Ciclo das Rochas": Um recurso lúdico para o ensino de Geociências. Campinas: Universidade Estadual de Campinas. (Dissert. de Mestrado).

Lopes O., Carneiro C. 2009. O jogo "Ciclo das Rochas" para o ensino de Geociências. Revista Brasileira de Geociências, 39: 30-41. 
Martins I., Veiga L., Teixeira F., Tenreiro-Vieira C., Vieira R., Rodrigues V., Couceiro F. 2007. Educação em ciências e ensino experimental. Formação de professores. Lisboa: Ministério da Educação, Direcção Geral de Inovação e Desenvolvimento Curricular.

Miguéns M. 1999. O Trabalho Prático e o Ensino das Investigações na Educação Básica. In: Conselho Nacional de Educação. ed. En sino Experimental e Construção de Saberes. Lisboa: Ministério da Educação, Conselho Nacional de Educação.

Miranda S. 2001. No fascínio do jogo, a alegria de aprender. Ciência Hoje, 28 (168): 64-66.

Negrine A. 2001. A ludicidade como ciência. In: S. Santos ed. A Ludicidade como Ciência Petrópolis: Vozes. p. 23-44.

Oliveira M. 1999. Trabalho Experimental e Formação de Professores. In: Conselho Nacional de Educação ed. Ensino Experimental e Construção de Saberes.
Lisboa: Ministério da Educação - Conselho Nacional de Educação.

Pessanha A. 2001. Actividade Lúdica Associada à Literacia. Lisboa: Instituto de Inovação Educacional.

Silvers S. 2005. Materials design for teaching English at the Junior High Level. Linguagem \& Ensino, 8(1):215-253.

Spradley J. 1980. Participant Observation. Orlando: Harcourt Brace Jovanovich.

Tamir P. 1991. Practical work in school science: an analysis of current practice. In: B. Woolnough ed. Practical science. Philadelphia: Open Univ. Press.

Teixeira C. 1995. A ludicidade na escola. São Paulo: Loyola.

Vygotsky L. 2002. A Formação Social da Mente. O desenvolvimento dos processos psicológicos superiores. São Paulo: Martins Fontes.

Wellington J. 1998. Practical Work in School Science. Which way now? London, New York: Routledge.

\section{NOTÍCIAS}

\section{Minerais e pedras preciosas do Brasil}

\author{
Silvia Fernanda de Mendonça Figueirôa \\ Depto. de Geociências Aplicadas ao Ensino \\ Instituto de Geociências/UNICAMP
}

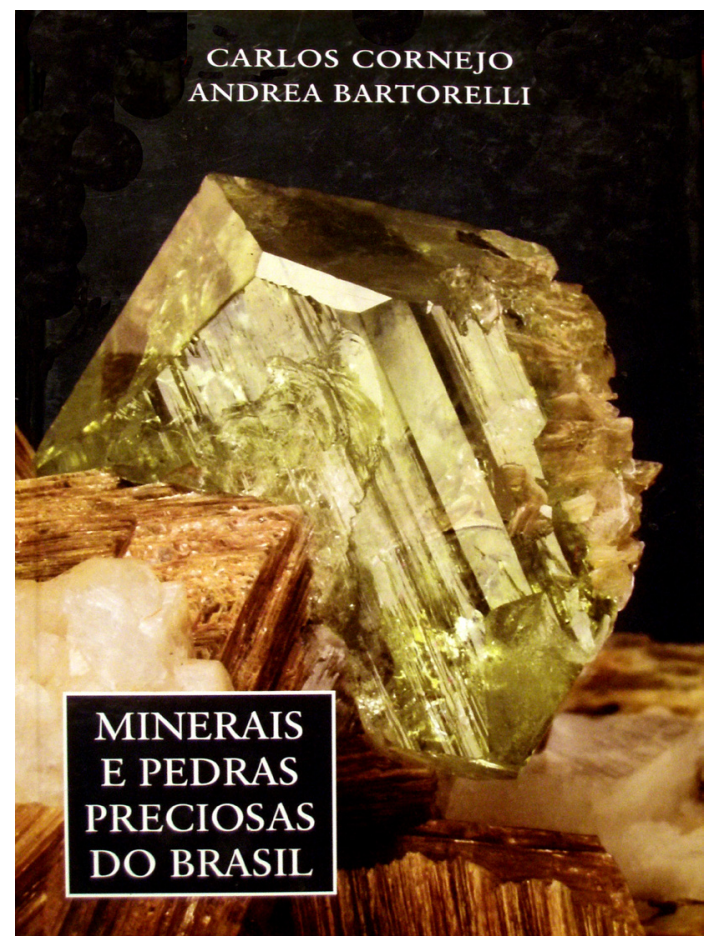


gemas aí aparecem em toda a sua exuberância e há imagens de tirar o fôlego. A segunda característica relevante é a abrangência espacial e temporal, que no caso encontram-se inter-relacionadas. Cornejo e Bartorelli partem da premissa, bastante correta, de que os minerais sempre estiveram presentes na vida das sociedades e civilizações. Assim, abrem o livro com capítulos dedicados ao período précolonial: "A arte lítica dos índios do Brasil", "Os ídolos e estatuetas dos sambaquis", "Objetos de arte lítica, ritual, artística e ornamental", e "Muiraquitã, a misteriosa pedra das Amazonas". Em todas as situações, sempre identificam as rochas e minerais brasileiros que foram utilizados.

O livro segue, adotando a linha cronológica, e passa a abordar com bastante detalhe o trabalho de José Bonifácio d'Andrada e Silva como mineralogista, além de outros naturalistas dos séculos XVIII e XIX, com ênfase nos estrangeiros que por aqui passaram ou aqui se estabeleceram por algum tempo, como o Barão von Eschwege ou ClaudeHenri Gorceix. As informações gerais seguem atualizadas até o presente, destacando alguns museus de fácil acesso e que exibem boas coleções, a saber: o Museu Nacional, o Museu de Ciências da Terra (ambos na cidade do Rio de Janeiro), o Museu de Ciência e Técnica da Escola de Minas de Ouro Preto (em Minas Gerais), o Museu de Geociências do Instituto de Geociências da USP e o Museu Geológico Valdemar Lefevre do Instituto Geológico de São Paulo (estes últimos situados na cidade de São Paulo). Ao final desta parte, um ponto alto: os itens consagrados às espécies minerais descritas no Brasil e, dentre estas, as que se encontram desacreditadas, são variedades ou sinônimas, numa oportuna atualização das decisões da IMA (International Mineralogical Association) a respeito.

Uma segunda parte, se assim podemos chamar, que ocupa os restantes cinqüenta por cento das páginas, passa a apresentar os minerais brasileiros segundo a classe a que pertencem: elementos nativos e ligas, sulfetos, haletos, óxidos e hidróxidos, carbonatos, sulfatos, fosfatos e arsenatos e, finalmente, silicatos e suas subclasses. Em todos os capítulos, a abordagem histórica se mantém, assim como uma listagem e apresentação das principais jazidas e garimpos de onde se extraíram esses minerais e gemas.

Em obra tão abrangente e detalhada, lamenta-se apenas a desatualização das fontes históricas utilizadas. Há já cerca de 25 anos a produção sobre a História das Ciências da Terra, particularmente da Geologia, vem crescendo com vigor e qualidade, com muitas dissertações e teses defendidas, livros e artigos publicados em boas revistas que estão disponíveis on-line. Uma consulta a esse material evitaria equívocos, como, por exemplo, a afirmação de que Bonifácio foi colega de turma, na Academia de Minas de Freiberg, de Alexander von Humboldt e de Wilhelm von Eschwege, pois o primeiro já havia saído quando de sua chegada e o segundo jamais estudou lá, mas sim em Clausthal. Mas nada que uma futura edição, para a qual seguramente haverá grande demanda, não possa dar conta. 